\title{
The Implications of the Monitor Theory for Foreign Language Teaching
}

\author{
Taher Bahrani \\ Department of English, Mahshahr Branch, Islamic Azad University, Mahshahr, Iran \\ E-mail: taherbahrani@yahoo.com
}

Received: May 7, $2011 \quad$ Accepted: June 13, $2011 \quad$ Published: October 1, 2011

doi:10.5539/ass.v7n10p281 URL: http://dx.doi.org/10.5539/ass.v7n10p281

\begin{abstract}
The most motivating as well as the most controversial theory which attempts to provide an overall account for second language acquisition is Krashen's Monitor Theory. This theory has had a huge effect on second language research and teaching since its emergence in the 1980s. However, despite this impact, it also received a great deal of criticism. Accordingly, the present paper attempts to provide a critical analysis of the theory's five main hypotheses. In addition, it aims at addressing the theory's implications for current EFL teaching by drawing on the researchers' experiences in the classroom as a teacher and as a student of English language.
\end{abstract}

Keywords: Monitor theory, Critical analysis, Implication, EFL teaching

\section{Introduction}

Krashen has frequently changed some elements in his theory which has undergone some stages of subsequent development. Without diving too deep into all these developments and refinements of his hypotheses, a description of the five main hypotheses of Krashen's theory in its mature stage will be given from various points of views first.

\subsection{The Acquisition-Learning Hypothesis}

The Acquisition-Learning Hypothesis suggests that adults have two different and independent systems of developing competence in a second language. One is acquisition which is subconscious and the other one is learning which is conscious (Gregg, 1984). Language acquisition is a process similar to the way a child learns his first language. Language acquirers are not consciously aware of the grammatical rules of the language. On the contrary, language learning refers to the conscious knowledge of a second language, knowing the rules, being aware of them, and being able to talk about them. Therefore, language learning takes place mostly in formal instruction. Krashen claims that these two systems should remain disparate (Krashen, 1981).

The Acquisition-Learning Hypothesis suggests that adults do not lose the ability to acquire languages the way that children do, since krashen claims that adults can access the same natural language acquisition device (LAD) that children use. He also assumes that learning does not turn into acquisition (Larsen-Freeman \&Long, 1991).

\subsection{The Natural Order Hypothesis}

The Natural Order Hypothesis states that the acquisition of grammatical structures happens in a predictable order. Some grammatical structures tend to be acquired early, some late. This occurs regardless to the first language of a given learner, the age and conditions of exposure.

This natural order does not necessarily depend on simplicity of form. In other words, this natural order dictates the way in which a language is acquired, but learning might follow another order (Gitsaki, 1998; Wilson, 2000).

\subsection{The Monitor Hypothesis}

The Monitor Hypothesis explains the relationship between acquisition and learning, and defines the influence of one on the other. This hypothesis holds that formal learning has only one function which is as a monitor for the learner's output.

The monitor functions properly when three specific conditions are met: 1 . there is sufficient time, 2. the focus of the interaction is on form rather than meaning, and 3. the learner knows the rule in question (Krashen, 1981; 
Schulz, 1991; Schutz, 2005). This monitoring involves self-correction on the base of learned language rules and is completely different from the monitoring during acquisition.

Krashen (1981) suggests that there is a difference among language learners regarding 'monitor' use. Accordingly, those learners who use the 'monitor' all the time are called over-users, those learners who have not learned or who prefer not to use their conscious knowledge are under-users and those learners who use the 'monitor' appropriately when it does not interfere with communication are optimal users.

\subsection{The Input Hypothesis}

The Input Hypothesis states that a language acquirer who is at "level I" must receive comprehensible input that is at "level $i+1 . "$ In other words, we acquire the language only when we understand language which contains structure that is 'a little beyond' our current level. This is achieved with the help of context or exralinguistic information (Gitsaki, 1998; Wilson, 2000).

Evidence for the input hypothesis can be found in the effectiveness of caretaker speech from an adult to a child, teacher-talk from a teacher to a language student, and foreigner-talk from a sympathetic conversation partner to a language learner/acquirer (Krashen, 1981). Krashen also provides the so-called 'silent period' as evidence for this hypothesis (Romeo, 2000).

A result of this hypothesis is that language learners should be given an initial 'silent period' during which they can build up acquired competence in the language before beginning to produce it.

\subsection{The Affective Filter Hypothesis}

The Affective Filter Hypothesis embodies Krashen's view that a number of affective factors play a facilitative role in second language acquisition. These factors are: motivation, self-confidence and anxiety.

Krashen claims that learners with high motivation, self-confidence, a good self-image, and a low level of anxiety are better equipped for success in second language acquisition. Low motivation, low self-esteem, and debilitating anxiety can combine to 'raise' the affective filter and form a 'mental block' that prevents comprehensible input from being used for acquisition. In other words, a high affective filter inhibits acquisition, whereas a low affective filter promotes it. According to Krashen, this filter is present in adults but not in children (Larsen-Freeman \& Long, 1991).

\section{A Critique of the Monitor Theory}

Now it is important to take a closer look at the criticisms that have arisen considering Krashen's theory. I believe that these criticisms stem from two essential issues. First, Krashen's theory was one of the first theories developed specifically to explain SLA. Second, his theory made a large number of claims about a wide array of SLA phenomena without providing any empirical evidence.

Serious concerns were first expressed by McLaughlin (1978), who acknowledges Krashen's attempt to develop an extensive and detailed SLA theory, but finds it inadequate in that some of its central assumptions and hypotheses are not clearly defined. As a result, they are not readily testable (Gitsaki, 1998). McLaughlin (1987) points out that Krashen never adequately defines acquisition, learning, conscious or subconscious which makes it extremely difficult to independently determine whether subjects are "learning" or "acquiring" language.

Gregg (1984) also criticizes Krashen's theory pointing out that it is too complex in that it asks us to believe that human language users have two completely separate systems: one for acquisition and one for learning.

Gregg (1984) notes that Krashen's use of the LAD gives it a much wider scope of operation than Chomsky's application. Krashen's insistence that "learning" cannot become "acquisition" is quickly refuted by the experience of anyone who has internalized grammar that was previously consciously memorized. Indeed, Krashen did not provide any evidence that people require two completely separate systems in order to learn a language. Furthermore, if two different systems for learning a language did exist, people would not be able to master a language in a formal setting only. Iran context services as a good example; many students succeed in learning English although they are exposed only to the foreign language in the formal classroom setting.

The second hypothesis is simply that grammatical structures are learned in a predictable order. Gregg (1984) argues that Krashen has no basis for separating grammatical morphemes from, for example, phonology or syntax. In addition, if individual differences exist, as discussed in 1.2, then the hypothesis is not provable or falsifiable and is, in the end, not useful.

The insufficiencies of this hypothesis become more apparent when examining it in terms of comprehension and production. Many studies into the order of acquisition, especially those in first language acquisition, are based on 
production. The fact that a learner uses a specific grammatical feature does not necessarily mean that he uses it appropriately, or that he understands how it works (McLaughlin, 1978, 1990). Moreover, it is not clear that the order is the same for comprehension and production. If these two processes differ in order, it is not clear how they would interact.

The Monitor Hypothesis holds that learning has only one function, which is to monitor the learner's output. McLaughlin (1978) points out that restricting learning to the role of editing production completely ignores comprehension. In fact, Krashen fails to take into account the role that monitoring plays in the reception of language.

Furthermore, Krashen not only does not explain how this monitor operates, but he also fails to prove that acquisition has no role in monitoring. McLaughlin raised these points in his criticism, but Krashen (1979) did not answer them in his reply (Romeo, 2000). In addition, Gregg points out that, by restricting monitor use to "learned" grammar and only in production, Krashen in effect makes the Acquisition-Learning Hypothesis and the Monitor Hypothesis contradictory. It is difficult to reconcile the contradiction since Krashen offers no evidence for either of these hypotheses.

Krashen's Input Hypothesis has also been criticized. McLaughlin claims that the concept of a learner's "level" is extremely difficult to define. I believe that educators also face difficulty in applying this rule in the classroom since individual differences come into play when determining the learners' current levels. Krashen did not provide solutions regarding this issue.

The Input Hypothesis maintains that increased input will result in more language acquisition, and that increased output will not. However, no clear empirical evidence exists for this assumption. In this regards, Romeo (2000) indicates that output of some kind is seen as a necessary phase in language acquisition. On the one hand, teachers need students' output in order to be able to judge their progress and adapt future materials to their needs. On the other hand, learners need the opportunity to use the L2 because when faced with communication failure, they are forced to make their output more precise.

These arguments suggest that, if comprehensible input is necessary, then so is comprehensible output. Yet this goes against Krashen's hypothesis.

Researchers note several problems with the Affective Filter Hypothesis as well. Krashen seems to indicate that the affective filter manifests itself at around the age of puberty. However, he does not make any serious attempts to explain how and why this filter develops only with the onset of puberty. Laser-Freeman and Long (1991) state that in order to provide empirical evidence, Krashen would need to specify which affect variables and at what levels. Clearly no explanation exists as to how this filter works.

In conclusion, some of Krashen's Monitor Theory's central assumptions and hypotheses are not clearly defined and, thus, are not readily testable or falsifiable.

\section{Implications for Foreign Language Teaching}

Krashen's Monitor Theory's influence on language education research and practice is absolutely undeniable. I will attempt to directly address what I consider to be some of the theory's implications for contemporary EFL teaching by drawing on my own experience in the classroom as a teacher and as a student of English language.

According to Krashen, classroom teaching benefits students when it provides the necessary comprehensible input to those students who are not yet at a level that enables them to receive comprehensible input from "the real world" or do not have access to "real world" language speakers. Classroom teaching can also help language learners by providing them with communication tools that enable them to make better use of the outside world, and when it provides beneficial conscious learning for optimal monitor users (Schulz, 1991).

In fact, I believe the implications of this input factor are considerable for foreign language teaching environments. The input factor points to the need for language proficiency on the part of the teacher, who is frequently the only live source of input (other than that provided by other learners) available to students. As a result, cooperative learning can be an excellent way for foreign language students to acquire comprehensible input from their peers. Second, the input factor points to the importance of instructional time in a conventional EFL program, suggesting that language institutions should increase program hours to provide more chance for language learners to have exposure to the language.

Our pedagogical goals should not only include supplying comprehensible input, but also creating a situation that encourages a low affective filter. The Input Hypothesis and the concept of the Affective Filter have redefined the effective language teacher as someone who can provide input and help make it comprehensible in a low anxiety 
situation (Wilson, 2000). I believe that the atmosphere of the language classroom must be friendly with the minimum amount of pressure. Language teachers can make a difference in students' motivation, anxiety levels, and self-images by respecting their students, listening to them, and taking note of what they say and what they want.

Furthermore, when teachers correct output at early stages of language learners, they may not help the student very much to learn from the correction made. The lack of in-class correction is a direct reflection of both the Affective Filter Hypothesis, which suggests creating a low anxiety learning environment, and the Natural Order Hypothesis, which claims that the teacher allows the natural order to take its place by allowing students' errors to occur. I agree with Krashen on this point; language learners lose their motivation if they are continuously corrected.

\section{Conclusion}

The present paper tried to review Krashen's Monitor Theory aiming at considering it implications in language learning. Accordingly, Krashen's Monitor Theory can be considered as an example of a macro theory attempting to cover most of the factors involved in second language acquisition, for example, age, personality traits, classroom instruction, innate mechanisms of language acquisition, environmental influences, input, and etc. Despite its popularity, the Monitor Theory has been criticized by theorists and researchers mainly on the grounds of its definitional adequacy. Moreover, Krashen's theory does not provide any empirical evidence regarding many claims such as $i+1$. However, despite these criticisms, Krashen's Monitor Theory has had significant impact on EFL teaching.

\section{References}

Gitsaki, C. (1998). Second language acquisition theories: overview and evaluation. Journal of Communication and International Studies, 4(2), 89-98.

Gregg, K. R. (1984). Krashen's Monitor and Occam's razor. Applied Linguistics, 5, 79-100. http://dx.doi.org/10.1093/applin/5.2.79

Krashen, S. (1981). Second language acquisition and second language learning. Oxford: Pergamon Press.

Larsen-Freeman, D., \& Long, M. (1991). An introduction to second language acquisition research. England: Longman.

McLaughlin, B. (1978). The monitor model: some methodological considerations. Language learning, 28, 309-332. http://dx.doi.org/10.1111/j.1467-1770.1978.tb00137.x

McLaughlin, B. (1990). Conscious versus unconscious learning. TESOL journal, 24, 617-634.

Romeo, K. (2000). Krashen and Terrell's "Natural Approach". [Online] Available: http://www.stanford.edu/ kenro/LAU/ICLangLit/NaturalApproach.htm (December 12, 2006)

Schulz, R. (1991). Second language acquisition theories and teaching practice: How do they fit? The Modern Language Journal, 75, 17-26. http://dx.doi.org/10.2307/329831

Schutz, R. (2005). Stephen Krashen's theory of second language acquisition. [Online] Available: http://www.sk.com.br/sk-krash.html (January 1, 2006)

Wilson, R. (2000). A summary of Stephen Krashen's "Principles and Practice in Second Language Acquisition". [Online] Available: http://www.languageimpact.com/articles/rw/krashenbk.htm (December 28, 2006) 